Volume 9, No.3, May - June 2020

International Journal of Advanced Trends in Computer Science and Engineering

Available Online at http:/www.warse.org/IJATCSE/static/pdf/file/ijatcs245932020.pdf

https://doi.org/10.30534/ijatcse/2020/245932020

\title{
Noninvasive Design of Low-Cost Foot Therapy BOT for Plantar Fasciitis
}

\author{
R Phani Vidyadhar, P Ganga Kiran, E Pranavi, J Ashwitha, JVR Ravindra \\ Center for Advance Research Laboratory (C-ACRL) \\ Department of Communication Engineering, Vardhaman College of Engineering \\ Shamshabad, Hyderabad, India \\ <rphaniv, gangakiran_16ec, epranavi_16ec, ashwitha_16ec,jvr.ravindra> @ vardhaman.org
}

\begin{abstract}
Plantar fasciitis or heel pain is one out and out of the premier basic reasons for heel torment. An aggravation of a thick band of tissue that associates the heel issue that remaining parts to be worked out toes. It brought about by redundant strain injury to the tendon of the base of the foot. Such strain injury is from over the top running or strolling and hopping injury from landing. Our task is to style an apparatus to hack back the aggravation of plantar fasciitis utilizing NI LabVIEW as a stage. The significant objective of the test is to grow the low expense foot treatment instrument for plantar fasciitis and other foot issues. The pivots and strain from this instrument give rest and decrease the hurt over the heel bone of the plantar fasciitis tissue. At the highest point of the endeavor, these serve to help doctors in diagnosing and treating heel torment with plantar fasciitis.
\end{abstract}

Key words : heel torment, LabVIEW, Plantar Fasciitis

\section{INTRODUCTION}

Plantar fasciitis is one of the most broadly perceived explanations behind heel torment. Foot issues are customary in middle-age people. It suffers for longer periods, and the feet have been invigorated after a clamoring day of human activity that doesn't resolve in solitude, by then it could be a sign of plantar fasciitis as shown in figure 1 [1].

Plantar Fascia is a thick tendon, goes about as protection and supports the bend of the foot, helping people walk. The plantar scarf is molded from three undeniable parts: the normal, central, and level gatherings [3]. The central plantar band is the thickest and most grounded zone and this bit is, also, the vital obligation to be incorporated into plantar fasciitis [16]. People who are encountering plantar fasciitis are extending nowadays. A couple of causes, for instance, diabetes, plantar fasciitis, etc. may be dissected. Ordinary prescriptions of Plantar fascia is essential for improving the patient's condition [9].

It is a structure of a contraption to diminish the disturbance of plantar fasciitis using NI LabVIEW as a phase. The essential purpose of the project is to develop a negligible exertion foot treatment device for plantar fasciitis and other foot issues. This device produces vibrations, hot temperatures, and cold temperatures over the plantar belt tissue, which gives loosening up and diminishes the torment over the heel bone. It serves to help specialists in treating and diagnosing heel torment and plantar fasciitis [19]. The individual gets an investigation of plantar fasciitis and rules from a moderate organization to support recovery, including fitting footwear at work, expanding, and manipulating [4].

\section{RELATED WORK}

Focusing on incapacitating waves in the mortal body is done either utilizing an $\mathrm{x}$-shaft or ultrasound picture isolation as proposed in [15]. Independent assessments have shown sketchy remedies coming to fulfillment because of ultrasound as proposed in [7]. Add a custom insole into the appropriate shoes of the plantar scarf, quiet for handling the glittering heap in an accurate position. This instantly wants to make a plantar point pressure viewable, which can quantitatively undeniably check the plantar point pressure persistently as proposed in [16]. Remarkable Ultrasound Therapy makes warm injury zones inside the delicate tissue of plantar fasciits, instantly starting a tissue fix comparable to the skin, gently moving collagen age [20]. It is sensible to naturally prompt an unimaginable modifying reaction in musculoskeletal tissue energizing and instantly recovering from the key injury as proposed in [6] [8]. To properly build up the acceptability of treatment by High-repeat Plantar Fascia and Lateral Epicondylitis as proposed in [5].

All the proposed works for treating plantar fasciitis properly utilized ultrasound treatment structures and utilized ultrasound waves to show up in connective tissues [11]. Over here we tentatively propose an effective treatment utilized to make diplomatic pressure and gradual enlargement of connective tissues using the thermoelectric modules [2].

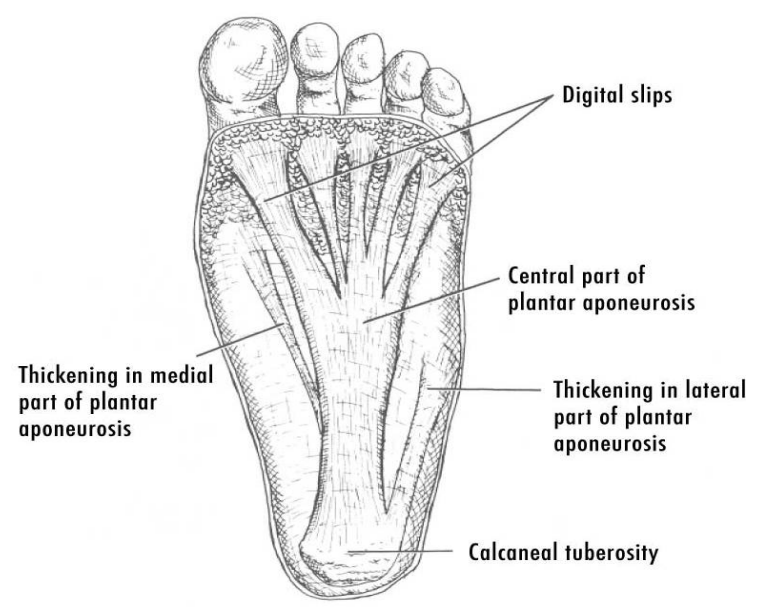

Figure 1: Plantar Fascia of the foot 


\section{IDENTIFICATION}

Plantar fasciitis causes an excruciating feeling inside the base of our foot. The moral agony is the most essential, with barely any means inside the morning, even though it can be activated by extensive stretches of standing, or at any point, you come up in the wake of sitting. The eternal torment is commonly more terrible. The most notable signs of plantar fasciitis are:

- Sharp or dull agony felt at the absolute bottom of the foot legitimately on or close to the impact point [10].

- Generally severe pain inside the morning, particularly when first standing.

- Fierce pain that declines after delayed weight-bearing.

- Heel expansion as well as solidness.

\subsection{DIAGNOSING}

Plantar fasciitis represents a clinical analysis. It is upholding the persistent history and physical tests. Patients can have neighborhood point delicacy along with the average tuberosity of the pain tormented by the essential advances, or in the wake of preparation. Plantar fascia torment procures an extremely limitless supply of the patient's pedal phalanges, which further stretches the plantar belt. Any action that may build a stretch of the plantar belt, such as strolling shoelessly without any help climbing steps can intensify the pain [13]. The clinical assessment will consider a patient's record of visible action, foot torment signs, and the sky represent the limit from there.

\subsection{WINDLASS TEST}

The Windlass Test could likewise represent an exceptional orthopedic test to intrigue side effects at the plantar sash by making maximal stretch: Imaging considerations like radiographs, analytic ultrasound, and MRI could likewise be valuable: Ultrasound can properly help analyze and guarantee plantar fasciitis through the view of the plantar belt thickness. The advantage of ultrasound is non-intrusive [14]. With more patient acknowledgment, financial savvy, and radiation [17]. The imaging apparatus ought to be right on the analysis and treatment of plantar fasciitis. The wearer is in a position with an MRI scanner and to accurately identify the fractional tears of the plantar belt, which is inside the position [12].

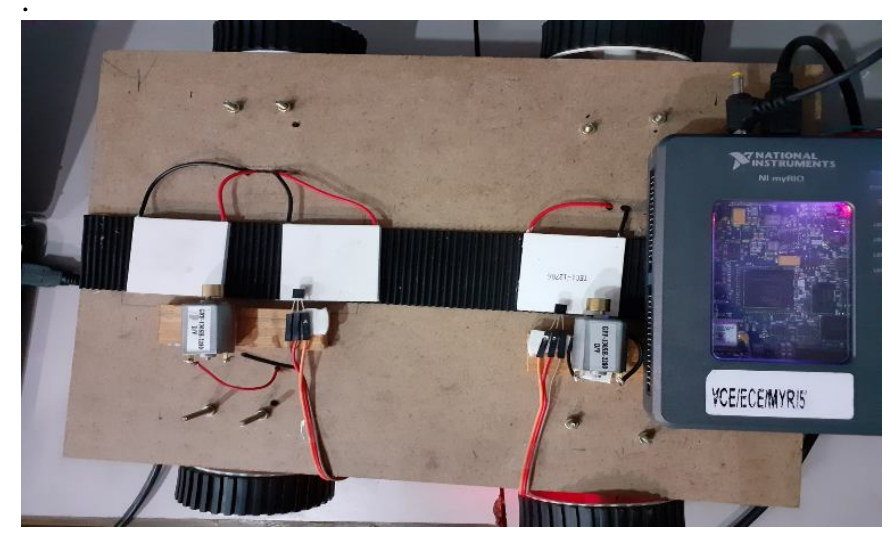

Figure 2: Experimental setup therapy BOT connectivity

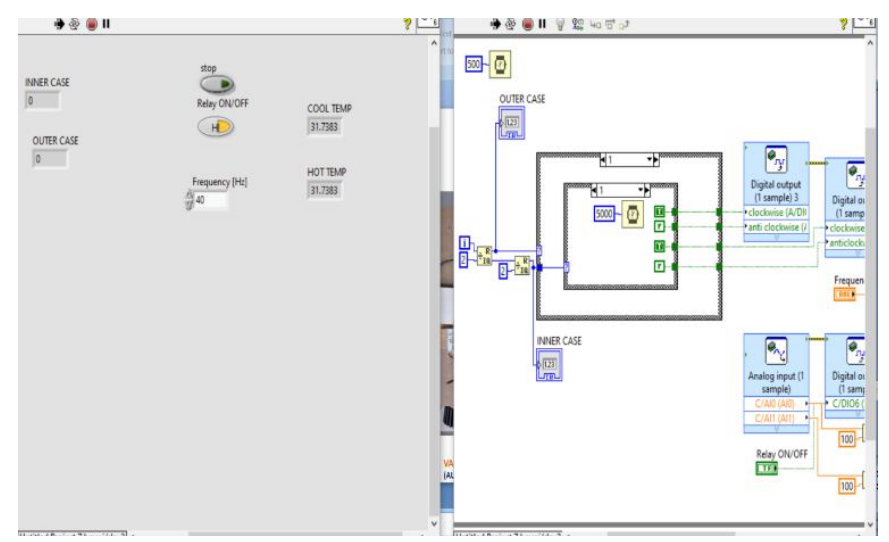

Figure 3: LabVIEW Coding using NI myRIO

\section{METHODOLOGY}

\subsection{Treatment designs}

The Plantar fasciitis treatment arrangement relies for the most part upon the vibrations and pressure made at the point of convergence of the heel bone. Two different methods are commonly used, generating vibrations and pressure and the contraction and expansion. The generation of vibrations of $80 \mathrm{~Hz}$ which also create pressure at the focusing point of heel bone gives relaxation for the tissues and it is produced by the vibration motors. This gentle vibration and pressure increment Lymphatic flow to expel acids from the Plantar Fascia. These Vibration Therapy assists with vibrating acids out of the connective tissues which cause agony or generous irritation. Automatic muscle withdrawals will likewise help tone and assemble powerless muscles in the legs and feet backing with improving equalization, coordination, and other conceivable lower furthest point issues. The contraction and expansion of tissues at the heel bone gives relaxation and the heel bone pain comes to the normal position. The expansion and contraction is produced by the thermo-electric module also called as peltier module which generates hot and cool temperature on either side of it. In regular time intervals these hot and cool sensation is supplied by the modules by acquiring the temperature at the peltier module and heel bone without reaching threshold temperature and simultaneously $16 \mathrm{psi}$ pressure is created by the vibration motors using the therapy BOT. These two treating strategies appear in Figure 2.

\subsection{Contraction and Expansion}

The contraction and expansion of tissues is the major part of the project whenever the thermoelectric module is on and started supply of hot and cool internally the plantar fascia tissue it starts releasing of the acids present in the heel bone. Due to these acidic substance the pain occurs. These temperature applications are utilized without a solution and it is a traditional method of standard medical treatment.

At the point when an individual injury a lower leg or pulls a ligament, it harms the delicate tissues at the influenced zone. The veins that flexibly oxygen and blood to the tissues are broken. The messed-up vessels at that point release 
fluctuating blood and serum into the tissues, which makes the influenced zone swell. Growing is an inclination of solidness, torment, and delicacy just as irritation. It applies the warmth and cold application in standard time interims. For instance, an individual ought to apply it for 1 moment and afterward evacuate it for an additional 30 seconds, so the skin isn't harmed from icing or stained from warming. We built up our warmth or cool treatment lash to control the temperature and the time we apply it.

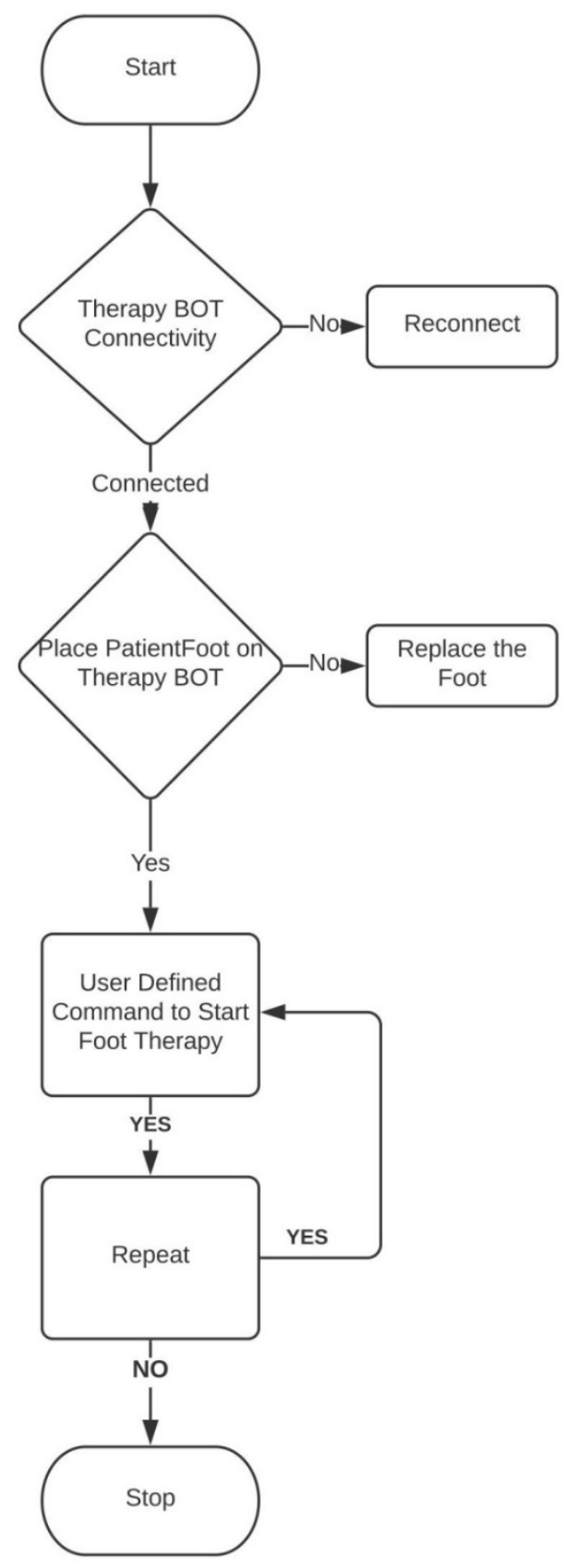

Figure 4: Therapy BOT Flow Chart.

\section{THERAPY BOT}

\subsection{Connectivity}

A Therapy BOT is designed as convenient to the foot of the patient as shown in the figure 3 . It is a moving BOT where it is controlled by the UI of the application using the NI myRIO as the software application. The BOT consists of $3 \mathrm{rpm}$ motors for the movement forward and backward. On the BOT there are four thermoelectric modules commonly known as peltier which generates heat and cool, it is connected to supply and myRIO for switching or triggering. There are two vibration motors which generates $80 \mathrm{~Hz}$ frequency as for the vibration therapy. The vibration motors are situated at the hallow space of the foot. It is associated to the myRIO for the function of signal. There is a temperature sensor LM35 which acquires the temperature present at the thermoelectric module. These BOT module is connected with Bluetooth for the wireless operation where the UI is responsible for the controlling the BOT.

\subsection{Working and Operation}

A Therapy BOT is connected and switched on in the UI of the application as shown in figure 2 and figure 4, A person foot is placed on the BOT as shown in figure 3 for the first minute of time cool temperature is supplied simultaneously vibration motors as rollers are activated and start vibrating and generates pressure at the heel of the foot. Whenever the temperature exceeds the threshold temperature (threshold temperature is the average human bearing temperature ) the cycle stops but the vibration motors works continuously. After a gap of 5 seconds the second cycle generation of heat for contraction is getting started these works simultaneously with regular intervals of time.

\section{EXPERIMENTAL ANALYSIS}

Heel torment is serious at 60 years old or more and individuals who experience all the more standing likewise have these torment at the age of over 35 . We do this test on such an age bunch who are encountering heel torment. This investigation is watched for about fourteen days. The ideal opportunity for the BOT is allowed as 2 minutes working of BOT produce a hot temperature for the initial 30 seconds and it provides the following 30 seconds cool sensation at the same time pressure is created by the vibration engines at the space of the foot. This proceeded for the second moment, also. It conveys this methodology for about fourteen days. We see this investigation in the first part of the day.

This test does an individual matured 67 felt more alleviation in the main week. The more mature individuals have high fragmentary tears at the heel. It completely fulfills the help from the treatment BOT is complete shown in table 1.

A female matured 60 is completed by this test felt help in the main week. As the partial tears are more at the heel and the help from the treatment BOT is fulfilled.

At 52, this analysis does an individual felt less alleviation in the principal week. As there are fewer tears at the heel and the help from the treatment BOT is fulfilled. 
A female of 35 is completed by this test felt as ordinary in the principal week because the more mature individuals have more agony at the heel and the help from the treatment BOT is sociable.

Table 1: Experimental analysis for Therapy BOT

\begin{tabular}{|l|l|l|l|c|c|}
\hline Method & Age & Sex & $\begin{array}{l}\text { Time in } \\
\text { minutes }\end{array}$ & $\begin{array}{l}\text { \% of Pain relief in } \\
\text { week 1 }\end{array}$ & $\begin{array}{l}\text { \% of Pain relief in } \\
\text { week 2 }\end{array}$ \\
\hline \multirow{5}{*}{ Therapy BOT } & 67 & Male & 2 minutes & $50 \%$ & $80 \%$ \\
\cline { 2 - 6 } & 60 & Female & 2 minutes & $40 \%$ & $80 \%$ \\
\cline { 2 - 6 } & 53 & Male & 2 minutes & $40 \%$ & $80 \%$ \\
\cline { 2 - 6 } & 52 & Female & 2 minutes & $40 \%$ & $80 \%$ \\
\cline { 2 - 6 } & 40 & Male & 2 minutes & $30 \%$ & $80 \%$ \\
\cline { 2 - 6 } & 47 & Male & 2 minutes & $40 \%$ & $80 \%$ \\
\cline { 2 - 6 } & 35 & Female & 2 minutes & $30 \%$ & \\
\hline
\end{tabular}

\section{RESULTS}

Treatment BOT is associated and turned on in the UI of the application is appeared in figure 2. An individual's foot is put on the BOT in figure 3 for the main moment the hot temperature is provided all the while vibration engines as rollers are initiated and begin vibrating and produce pressure at the impact point of the foot. At whatever point the temperature surpasses the edge temperature ( edge temperature is the normal human bearing temperature ) the cycle stops yet the vibration engines work constantly. Following a hole of 5 seconds, the second cycle age of warmth for compression is beginning these works all the while with ordinary interims of time.

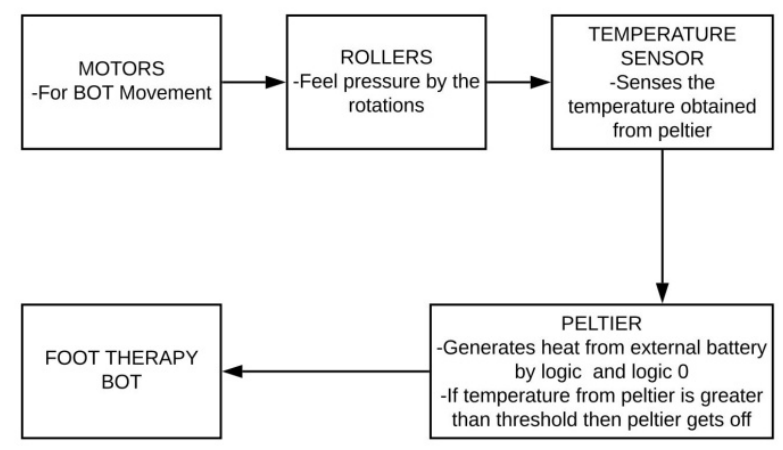

( Threshold temperature varies according to the person on average the threshold temperature is $35^{\circ} \mathrm{c}$ )

Figure 5: Block Diagram for Experimental setup

A Therapy BOT is planned as advantageous to the foot of the patient as indicated by the above block diagram, as appeared in figure 5. The moving BOT contain motors, vibration motors are as rollers which are utilized to get the weight and vibrations, and the temperature is estimated and used to control the use of the BOT these are completely associated with the thermoelectric module which produces warmth and cool either side of it, it is associated by the UI of the application utilizing the myRIO and LabVIEW as the product application. The BOT pushes ahead and in reverse for warmth and cool application. The vibration engines or the rollers are arranged at the space of the foot. It is related to myRIO for the capacity of the sign. The temperature sensor which procures the temperature present at the thermoelectric module. This BOT module is associated with Bluetooth for the remote activity where the UI is liable for controlling the BOT.

\section{CONCLUSION}

The Low-cost foot treatment framework is effectively actualized to make the degree of tissue help. The LabVIEW coding is effectively developed to produce vibrations, make weight and produce warmth and cool temperature by securing the temperature from this gadget gives unwinding and diminishes the torment over the heel bone of the plantar fasciitis tissue. Other than that, the LabVIEW UI and Therapy BOT gadget are effectively developed to show the temperature and the catches.

\section{ACKNOWLEDGEMENTS}

This research project was funded by Department of Science and Technology (DST), India under the grant No: SEED/TIDE/031/2017/G/C.

\section{REFERENCES}

1. Your guide for plantar fasciitis by Heel that pain (e-book).

2. J. Gao, L. Xu, A. Bouakaz and M. Wan, "A Deep Siamese-Based Plantar Fasciitis Classification Method Using Shear Wave Elastography," in IEEE Access, vol. 7, pp. 130999-131007, 2019, doi: 10.1109/ACCESS.2019.2940645.

3. A. Numchaichanakij, K. Chitsakul and S. Tretriluxana, "An insole point pressure monitoring system," The 4th 2011 Biomedical Engineering International Conference, Chiang Mai, 2012, pp. 198-201, doi: 10.1109/BMEiCon.2012.6172051.

4. I. Manousakas, L. R. Wan and S. M. Liang, "Targeting Shock Waves in human tissue for Extracorporeal Shock Wave Therapy," The 26th Annual International Conference of the IEEE Engineering in Medicine and Biology Society, San Francisco, CA, 2004, pp. 3489-3491, doi: 10.1109/IEMBS.2004.1403979.

5. E. G. McNally and S. Shetty, "Plantar fascia: Imaging diagnosis and guided treatment," in Seminars in Musculoskeletal Radiology, vol. 14. Stuttgart, Germany: Thieme Medical Publishers, 2010, no. 3, pp. 334343.

6. Slayton, M. H., Baravarian, B., Amodei, R. C., Compton, K. B., Christensen, D. N., McNelly, A., \& Latt, L. D. (2019). Intense Therapeutic Ultrasound for Pain Relief in the Treatment for Chronic Plantar Fasciopathy. Foot \& Ankle Orthopaedics. https://doi.org/10.1177/2473011419862228.

7. I. Manousakas, L. R. Wan and S. M. Liang, "Targeting Shock Waves in human tissue for Extracorporeal Shock Wave Therapy," The 26th Annual International Conference of the IEEE Engineering in Medicine and 
Biology Society, San Francisco, CA, 2004, pp. 3489-3491, doi: 10.1109/IEMBS.2004.1403979.

8. Shu, Lin \& Hua, Tao \& Wang, Yangyong \& Li, Qiao \& Feng, David Dagan Feng \& Tao, Xiaoming. (2010). In-Shoe Plantar Pressure Measurement and Analysis System Based on Fabric Pressure Sensing Array. IEEE transactions on information technology in biomedicine : a publication of the IEEE Engineering in Medicine and Biology Society. 14. 767-75. 10.1109/TITB.2009.2038904.

9. N. K. Rana, "Application of Force Sensing Resistor (FSR) in Design of Pressure Scanning System for Plantar Pressure Measurement," 2009 Second International Conference on Computer and Electrical Engineering, Dubai, 2009, pp. 678-685, doi: 10.1109/ICCEE.2009.234.

10. M. H. Slayton, R. C. Amodei, K. B. Compton, D. Latt and J. Kearney, "Musculoskeletal treatments using intense therapy ultrasound: Clinical studies for chronic plantar fasciitis and lateral epicondylitis," 2016 IEEE Healthcare Innovation Point-Of-Care Technologies Conference (HI-POCT), Cancun, 2016, pp. 208-211, doi: 10.1109/HIC.2016.7797733..

11. M. T. Teechot, M. A. Maneerat, M. I. Sansutnanont, M. O. Ornketphon, M. T. Treebupachatsakul and C. Pintavirooj, "Force Sensor for Measuring Plantar Pressure," 2019 12th Biomedical Engineering International Conference (BMEiCON), Ubon Ratchathani, Thailand, 2019, pp. 1-3, doi: 10.1109/BMEiCON47515.2019.8990304.

12. K. Wang, J. Liu, J. Wu, Z. Qian, L. Ren and L. Ren, "Noninvasive in Vivo Study of the Morphology and Mechanical Properties of Plantar Fascia Based on Ultrasound," in IEEE Access, vol. 7, pp. 53641-53649, 2019, doi: 10.1109/ACCESS.2019.2909409.

13. J. Tilles, A. Shaporev and V. Reukov, "mHealth Musculoskeletal Applications: Bluetooth Low Energy Devices and Android," 2016 32nd Southern Biomedical Engineering Conference (SBEC), Shreveport, LA, 2016, pp. 111-112, doi: 10.1109/SBEC.2016.61.

14. Y. Yang, G. Yu, S. Huang, M. Wang, W. Niu and Z. Ding, "Effect of the Plantar Fasciotomy on the Movement of the Foot Arch," 2007 1st International Conference on Bioinformatics and Biomedical Engineering, Wuhan, 2007, pp. 478-481, doi: 10.1109/ICBBE.2007.126.

15. G. Yarnitzky, Z. Yizhar and A. Gefen, "Real-time monitoring of internal deformations in the soft tissues of the foot: a new approach in gait analysis," 2004 23rd IEEE Convention of Electrical and Electronics Engineers in Israel, Tel-Aviv, Israel, 2004, pp. 173-176, doi: 10.1109/EEEI.2004.1361117.

16. I. Nam, M. Lee, Y. Kim, J. Shin, Y. S. Lee and Y. Chung, "The effects of foot position on erector spinae and gluteus maximus muscle activation during sit-to-stand in persons with stroke," 2014 IEEE 19th International Functional Electrical Stimulation Society Annual Conference (IFESS), Kuala Lumpur, 2014, pp. 1-3, doi: 10.1109/IFESS.2014.7036732.
17. A. Gefen, M. Megido-Ravid, Y. Itzchak and M. Arcan, "Integrating biomechanical tools to support foot physical therapy," Proceedings of the 22nd Annual International Conference of the IEEE Engineering in Medicine and Biology Society (Cat. No.00CH37143), Chicago, IL, 2000, pp. 3164 vol.4-, doi: 10.1109/IEMBS.2000.901558.

18. al-Qerem, Ahmad. (2019). Circular Shape Formation using Self Adaptive Collective Motion of Swarm Robots. International Journal of Advanced Trends in Computer Science and Engineering. 8. 2054-2061.

19. Putra, R. R. (2019). A Naïve Bayes Sentiment Analysis for Fintech Mobile Application User Review in Indonesia. International Journal of Advanced Trends in Computer Science and Engineering, 1856-1860. doi: 10.30534/ijatcse/2019/07852019

20. Manaa, S. A. (2019). Residual Power Series Method for Solving Kaup-Boussinesq System. International Journal of Advanced Trends in Computer Science and Engineering, 8(5), 2089-2095. doi: 10.30534/ijatcse/2019/36852019 